Discussion Paper No. 697

\title{
DOES PRO-POPULATION POLICY RAISE PER CAPITA CONSUMPTION?
}

\author{
Ken-ichi Hashimoto \\ and \\ Yoshiyasu Ono
}

\begin{abstract}
July 2007
The Institute of Social and Economic Research Osaka University

6-1 Mihogaoka, Ibaraki, Osaka 567-0047, Japan
\end{abstract}




\title{
Does Pro-population Policy Raise Per Capita Consumption?*
}

\author{
by \\ Ken-ichi Hashimoto ${ }^{\dagger}$ and Yoshiyasu Ono ${ }^{\ddagger}$
}

\begin{abstract}
We theoretically analyze the effects of a child allowance, an improvement in the efficiency of child rearing and a labor income tax on the fertility rate and per capita consumption. The effects on per capita consumption are opposite in the absence, and the presence, of unemployment. For example, a child allowance urges people to have more children and allocate more labor to child rearing, decreasing labor supply for the purpose of commodity production. Therefore, under full employment, it decreases per capita consumption. In the presence of unemployment, however, it reduces the deflationary gap and hence stimulates per capita consumption.
\end{abstract}

Keywords: child allowance, child rearing, endogenous fertility, wage income tax, unemployment

JEL Classification Number: E24, J13

* Hashimoto’s research is financially supported by the Grants-in-Aid for Young Scientists (B), JSPS. Ono’s research is financially supported by the Grants-in-Aid for Scientific Research, JSPS.

${ }^{\dagger}$ Graduate School of Economics, Kobe University, 2-1 Rokko-dai, Nada, Kobe 657-8501, JAPAN. E-mail: hashimoto@econ.kobe-u.ac.jp

‡ Institute of Social and Economic Research, Osaka University, 6-1, Mihogaoka, Ibaraki, Osaka 567-0047, JAPAN. E-mail: ono@iser.osaka-u.ac.jp 


\section{Introduction}

Many developed countries nowadays face low fertility rates, e.g., France (1.91), Germany (1.36), Italy (1.33), Britain (1.63) Sweden (1.75), and carry out various policies to improve childcare environment. ${ }^{1}$ Among these countries Japan's rate is particularly low (1.29). Japan considers a low fertility rate to be a major obstacle for economic growth and subsidizes child rearing (the Parental Leave Act in 1992). However, an increase in the number of children generates costs as well as benefits. It not only increases total labor supply in the future, but also requires present child-rearing services. Thus, it decreases labor allocation for commodity production, which reduces per capita consumption if full employment is realized. In the presence of unemployment, however, the decrease in the individual labor supply shrinks the deflationary gap so that per capita consumption may increase.

This paper focuses on such a difference in the employment situation and examines the effects of a child-rearing subsidy, an improvement in the efficiency of child rearing (nursery schools, kindergartens, etc.) and a labor income tax on the fertility rate and per capita consumption. We find that the effects on individual consumption are opposite for the cases of full employment and unemployment, and hence the employment situation must be taken into account when considering a pro-population policy.

Becker and Lewis (1973), Razin and Ben-Zion (1975), Becker and Barro (1988), Palivos (1995) and Cai (2001) assume that the number of children affects utility and analyze the effects on fertility and consumption of child-rearing costs, public support for child rearing, productivity and preferences in a static and dynamic setting. ${ }^{2}$ Yip and Zhang $(1996,1997)$, Tamura (1996) and Tabata (2003) extend them to an endogenous growth framework and examine the impact of demographic transition on growth and welfare. Petrucci (2003) introduces endogenous fertility to a Sidrauski (1967) type monetary model and finds that the neutrality of money is invalid, i.e., monetary policy changes the fertility rate, labor supply, consumption and capital. However, all of the abovementioned studies ignore the possibility of

\footnotetext{
${ }^{1}$ The fertility data are those of 2004 from OECD (2006). See Atoh and Akachi (2003) for an international comparison of family policies.

${ }^{2}$ Nerlove et al. (1987, ch. 5), Razin and Sadka (1995) and Nerlove and Raut (1997) provide useful surveys of various approaches to endogenous fertility. For empirical evidence in support of the endogeneity of fertility choice, see Wang et al. (1994).
} 
unemployment. ${ }^{3}$ To fill this void, we theoretically analyze the effects of pro-population policies in the presence of unemployment and compare them with those under full employment.

The remainder of the paper is organized as follows. Section 2 outlines the basic structure of the model. The dynamics and steady state conditions are shown in section 3. Section 4 focuses on the full-employment steady state and examines the effects of the abovementioned policies on per capita consumption. Section 5 considers the case where unemployment occurs in the steady state, which is presented by Ono (1994, 2001), and shows the effects of the policies are just opposite to those that arise under full employment. Finally, section 6 concludes the paper.

\section{The Model}

We consider a competitive monetary economy populated by infinitely lived households. At each point in time, they determine consumption $c$, real money balances $m$, and the number of children $n$ that satisfies

$$
\dot{N}=n N \text {, }
$$

where $N$ represents the population size. Each household's lifetime utility is

$$
U(c, n, m)=\int_{0}^{\infty}[u(c)+f(n)+v(m)] \exp (-\rho t) d t,
$$

where $u(\cdot), f(\cdot)$ and $v(\cdot)$ satisfy the following properties:

$$
u^{\prime}(\cdot)>0, u^{\prime \prime}(\cdot)<0 ; f^{\prime}(\cdot)>0, f^{\prime \prime}(\cdot)<0 ; v^{\prime}(\cdot)>0, v^{\prime \prime}(\cdot) \leq 0 \text {. }
$$

He (or she) allocates labor endowment, which is normalized to unity, to child rearing and labor market activities. Labor input $\gamma h(n)$ is required to bear and raise each child, where $\gamma$ represents the inefficiency parameter of child rearing and $h(n)$ is assumed to satisfy

$$
h^{\prime}(n)>0, h^{\prime \prime}(n)>0
$$

The rest is the labor supply to the market:

\footnotetext{
${ }^{3}$ An exception is Blau and Robins (1989). They empirically investigate the impact of child-care costs on fertility and employment using a household survey of employment opportunity pilot projects.
} 


$$
[1-\gamma h(n)] N \text {. }
$$

The government imposes lump-sum tax $z$ and wage income tax $s$, and gives child allowance $\tau$ to each household. Thus, each household's flow and stock budget equations are

$$
\begin{gathered}
\dot{a}=r a+(1-s) w[1-\gamma h(n)] x-c-R m+\tau n-z, \\
a=m+b,
\end{gathered}
$$

where $a$ represents real total assets, $r$ and $R$ the real and nominal interest rates respectively, $w$ the real wage, $x$ the employment ratio and $b$ the real value of equities. ${ }^{4}$ Given labor demand $L$, $x$ is represented by

$$
x=\min \left(1, \frac{L}{[1-\gamma h(n)] N}\right) .
$$

Maximizing lifetime utility $U$ given by (1) subject to (3) yields the first-order optimal conditions:

$$
\begin{gathered}
u^{\prime}(c)=\delta, \\
v^{\prime}(m)=R \delta, \\
f^{\prime}(n)=\delta\left[(1-s) w \gamma h^{\prime}(n) x-\tau\right], \\
\dot{\delta}=(\rho-r) \delta,
\end{gathered}
$$

and the transversality condition:

$$
\lim _{t \rightarrow \infty} \delta a \exp (-\rho t)=0
$$

where $\delta$ is the co-state variable of $a$.

From the conditions given by (4), we derive

$$
\begin{gathered}
\rho+\sigma \frac{\dot{c}}{c}+\pi=R=v^{\prime}(m) / u^{\prime}(c), \\
\tau+\frac{f^{\prime}(n)}{u^{\prime}(c)}=(1-s) w \gamma h^{\prime}(n) x,
\end{gathered}
$$

where

$$
\sigma \equiv-u^{\prime \prime}(c) c / u^{\prime}(c)
$$

\footnotetext{
${ }^{4}$ It is later shown that the firm value is zero because a constant-returns-to-scale technology is assumed.
} 
We assume $\sigma$ to satisfy ${ }^{5}$

$$
\sigma \geq 1 \text {. }
$$

The firm sector has a production function with constant returns to scale:

$$
Y=\theta L,
$$

where $Y$ represents output and productivity $\theta$ is assumed to be constant. Given nominal commodity price $P$ and nominal wage $W$, the firm sector determines labor demand $L$ so as to maximize profits $(P \theta-W) L$. Under perfect adjustment of $P$ it is always valid that

$$
w=\theta,
$$

and thus profits are always zero, implying that the firm value is zero.

The government establishes such a social security system that the same level of wealth as held by an existing household is given to each newly born household. It imposes lump-sum tax $z$ and wage income tax $s$ to finance the initial setup wealth for newly born households and child allowances. ${ }^{6}$ Money stock $M^{5}$ is assumed to expand proportionately to population size $N$ so that the effect of monetary policy is neutralized, i.e.,

$$
\frac{\dot{M}^{s}}{M^{s}}=\frac{\dot{N}}{N}=n
$$

The government's budget constraint is then

$$
P z N+P s w[1-\gamma h(n)] x N=P \tau n N+A n N-\dot{M}^{s},
$$

which reduces to

$$
z+s w[1-\gamma h(n)] x=(\tau+a) n-n M^{s} /(P N)
$$

Given such household, firm and government behavior as mentioned above, the money and equity markets perfectly adjust so that at any point in time ${ }^{7}$

$$
\text { the money market: } m N=M^{\mathrm{s}} / P \text {, }
$$

\footnotetext{
${ }^{5}$ In fact, Hall (1988) and Guvenen (2006) empirically show $1 / \sigma$ to be much smaller than 1.

${ }^{6}$ Developed countries tend to have a mature public redistribution system while developing countries tend to redistribute wealth to the next generation within each family. For simplicity, we assume that a complete public redistribution system is established so that each household does not privately care about the initial wealth of the next generation.

${ }^{7}$ Because of Walras' law for stock variables, (12) is valid if (11) holds.
} 
The commodity market adjustment is also assumed to be perfect, and hence

$$
c=\theta[1-\gamma h(n)] x .
$$

In contrast, the nominal wage adjustment is sluggish so that we can treat the possibility of unemployment. ${ }^{8}$ It is simply represented by

$$
\frac{\dot{W}}{W}=\alpha(x-1)
$$

where $\alpha$ represents the adjustment speed of nominal wage $W$ and $x$ is given by (13).

\section{Dynamics and Steady State Conditions}

From (6), (9) and (13), $n$ is derived as a function of (c, $\tau, s, \gamma)$ :

$$
n=n(c ; \tau, s, \gamma) \Leftrightarrow \tau+\frac{f^{\prime}(n)}{u^{\prime}(c)}=(1-s) \frac{\gamma h^{\prime}(n)}{1-\gamma h(n)} c .
$$

Using (7) and (15), we find that as long as $\tau$ and $s$ are small enough, the partial derivatives of $n$, represented by $n_{q}$ for $q=c, \tau, s$ and $\gamma$, satisfy

$$
\begin{gathered}
n_{c}=(\sigma-1) f^{\prime}(n) /\left[\Phi u^{\prime}(c) c\right]>0, \\
n_{\tau}=1 / \Phi>0, \\
n_{s}=c \gamma h^{\prime}(n) /\{\Phi[1-\gamma h(n)]\}>0, \\
n_{\gamma}=-c h^{\prime}(n) /\left\{\Phi[1-\gamma h(n)]^{2}\right\}<0, \\
\text { where } \Phi \equiv \frac{-f^{\prime \prime}(n)}{u^{\prime}(c)}+\frac{\gamma h^{\prime \prime}(n)(1-\gamma h(n))+\left(\gamma h^{\prime}(n)\right)^{2}}{(1-\gamma h(n))^{2}} c>0 .
\end{gathered}
$$

From (2) and (8), the production capacity per capita is

$$
y^{f}(c ; \tau, s, \theta, \gamma)=\theta[1-\gamma h(n)]
$$

where $n$ is given by (15). From (16) and (17), in the neighborhood where $\tau=0$,

\footnotetext{
${ }^{8}$ This assumption is imposed merely to allow disequilibrium to occur in the labor market; otherwise, the possibility of unemployment is intrinsically avoided. Note that under this assumption the possibility of a full employment steady state is not eliminated. In fact, section 4 obtains the full employment steady state under it.
} 


$$
\begin{gathered}
y_{c}^{f}=-\theta \gamma h^{\prime}(n) n_{c}<0, \quad y_{\tau}^{f}=-\theta \gamma h^{\prime}(n) n_{\tau}<0, \\
y_{s}^{f}=-\theta \gamma h^{\prime}(n) n_{s}<0, \quad y_{\theta}^{f}=1-\gamma h(n)>0, \\
y_{\gamma}^{f}=-\theta\left[h(n)+\gamma h^{\prime}(n) n_{\gamma}\right]=\frac{1}{\Phi} \frac{\theta h(n) f^{\prime}(n)}{u^{\prime}(c)}\left\{\frac{h^{\prime}(n)}{h(n)}-\frac{h^{\prime \prime}(n)}{h^{\prime}(n)}+\frac{f^{\prime \prime}(n)}{f^{\prime}(n)}\right\}_{<}^{>}=0,
\end{gathered}
$$

where $y_{q}^{f}$ represents $\partial y^{f} / \partial q$ for $q=c, \tau, s, \theta$ and $\gamma$. Note that $y_{\gamma}^{f}$ can be either positive or negative, depending on the functional forms of $h(n)$ and $f(n)$. For example, if

$$
h(n)=n^{\eta} \text { where } \eta>1, \quad f(n)=e n^{1-v} /(1-v) \text { where } e>0,
$$

then

$$
h^{\prime}(n) / h(n)-h^{\prime \prime}(n) / h^{\prime}(n)+f^{\prime}(n) / f^{\prime}(n)=(1-v) / n,
$$

i.e., $y_{\gamma}^{f}$ is either positive or negative depending on whether or not $v$ is smaller than 1 .

Since (9) implies that $P$ moves parallel to $W$, from (13), (14) and (17), the dynamics of $P$ is

$$
\pi \equiv \frac{\dot{P}}{P}=\alpha(x-1)=\alpha\left[c / y^{f}(c ; \tau, s, \theta, \gamma)-1\right]
$$

By applying this equation into (5) we obtain the dynamics of $c$ :

$$
\sigma \frac{\dot{c}}{c}=v^{\prime}(m) / u^{\prime}(c)-\rho-\alpha\left[c / y^{f}(c ; \tau, s, \theta, \gamma)-1\right] .
$$

From (10), (11) and (19), the dynamics of $m$ is

$$
\frac{\dot{m}}{m}=-\alpha\left[c / y^{f}(c ; \tau, s, \theta, \gamma)-1\right]
$$

Equations (20) and (21) form an autonomous dynamic system with respect to $c$ and $m$.

In the steady state $c$ stays constant and hence (20) yields

$$
v^{\prime}(m) / u^{\prime}(c)=\rho+\alpha\left[c / y^{f}(c ; \tau, s, \theta, \gamma)-1\right]
$$

Note that this property is valid whether or not full employment is realized.

\section{The Case of Full Employment}

Under full employment $x$ equals 1 and hence from (13), (17) and (22), 


$$
\begin{aligned}
c^{f}=y^{f}\left(c^{f} ; \tau, s, \theta, \gamma\right) & =\theta[1-\gamma h(n)], \\
v^{\prime}(m) / u^{\prime}\left(c^{f}\right) & =\rho,
\end{aligned}
$$

where $c^{f}$ represents the per capita consumption under full employment. From the first equation of (23),

$$
\left(1-y_{c}^{f}\right) d c^{f}=y_{\tau}^{f} d \tau+y_{s}^{f} d s+y_{\theta}^{f} d \theta+y_{\gamma}^{f} d \gamma
$$

Since $y_{c}^{f}<0$, as shown in (18), this equation gives

$$
\operatorname{sgn} d c^{f} / d i=\operatorname{sgn} y_{i}^{f} \quad \text { for } i=\tau, s, \theta, \gamma \text {, }
$$

and thus from (18) we find

$$
\begin{gathered}
\tau \uparrow, s \uparrow, \theta \downarrow \Rightarrow c^{f} \downarrow \\
\gamma \uparrow \Rightarrow c^{f \uparrow} \quad \text { iff } \frac{h^{\prime}(n)}{h(n)}-\frac{h^{\prime \prime}(n)}{h^{\prime}(n)}+\frac{f^{\prime \prime}(n)}{f^{\prime}(n)}>0 .
\end{gathered}
$$

Since the total differentiation of the first equation in (23) gives

$$
\theta \gamma h^{\prime}(n) d n=\left(c^{f} / \theta\right) d \theta-\theta h(n) d \gamma-d c^{f},
$$

and (15) implies $d c^{f}$ to satisfy

$$
d n=n_{c} d c^{f}+n_{\tau} d \tau+n_{s} d s+n_{\gamma} d \gamma,
$$

$d n$ satisfies

$$
\left(1+n_{c} \theta \gamma h^{\prime}(n)\right) d n=n_{c}\left(c^{f} / \theta\right) d \theta+\left(n_{\gamma}-\theta h(n) n_{c}\right) d \gamma+n_{\tau} d \tau+n_{s} d s
$$

Therefore, from (16)

$$
\tau \uparrow, s \uparrow, \theta \uparrow, \gamma \downarrow \Rightarrow n \uparrow .
$$

The properties given by (25) and (27) are summarized as follows:

Proposition 1. If full employment is realized in the steady state, an increase in child allowance

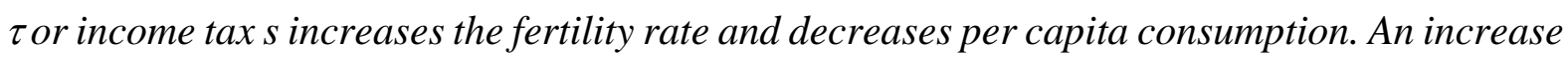
in productivity $\theta$ increases both the fertility rate and per capita consumption. An increase in the efficiency of child rearing (viz. a decrease in $\gamma$ ) always increases the fertility rate, but the effect on per capita consumption is ambiguous. More precisely, 


$$
\begin{aligned}
d c^{f} / d \gamma & =0 \text { iff } \frac{h^{\prime}(n)}{h(n)}-\frac{h^{\prime \prime}(n)}{h^{\prime}(n)}+\frac{f^{\prime \prime}(n)}{f^{\prime}(n)}=0 . \\
& <
\end{aligned}
$$

Intuitively, a rise in child allowance $\tau$ or wage tax $s$ reduces the opportunity cost of child rearing, causing people to raise more children and reduce labor supply to the market. Thus, $n$ increases and $c$ declines. A change in $\gamma$ has two opposite effects on $c^{f}$. A decrease in $\gamma$ (viz. an improvement in the efficiency of child rearing) directly increases labor supply and thus raises $c^{f}$. However, it increases fertility rate $n$, causing labor supply to fall and thus $c^{f}$ to decrease. Therefore, the total effect of a change in $\gamma$ is ambiguous.

\section{The Case of Stagnation under a Liquidity Trap}

We next consider the case where a liquidity trap arises and unemployment persistently remains, as presented by Ono (1994, 2001), and compare the effects of the abovementioned policies and parameter changes with those in the case of full employment.

Money demand is given by the second equality of (5):

$$
R=v^{\prime}(m) / u^{\prime}(c) .
$$

Thus, a liquidity trap arises if the representative household has an insatiable desire to hold money:

$$
\lim _{m \rightarrow \infty} v^{\prime}(m)=\beta>0,
$$

where $\beta$ is an exogenous and positive constant. ${ }^{9}$ Figure 1 illustrates the money demand curve in this case.

In the presence of the liquidity trap the second equation of (23) may be invalid for any $m$. It is indeed the case if

$$
\rho<\beta / u^{\prime}\left(c^{f}\right)\left(<v^{\prime}(m) / u^{\prime}\left(c^{f}\right) \text { for any } m\right),
$$

\footnotetext{
${ }^{9}$ See Ono (1994: 4-8) for discussions on the insatiable utility of money in the history of economic thought (e.g., Veblen, Marx, Simmel, Keynes) and its economic implications. The validity of this property is empirically supported by Ono (1994: 34-8) using the GMM (generalized method of moments), and more extensively by Ono, Ogawa and Yoshida (2004) using both parametric and non parametric methods.
} 
i.e., the full-employment steady state does not exist. In this case a stagnation steady state is the only steady state, as proved by Ono $(1994,2001)$. Because of persistent unemployment $P$ continues to decline and hence $v^{\prime}(m)$ converges to $\beta$. Thus, the steady state level of $c$ that satisfies (22) is given by the intersection point of the following two curves:

$$
\begin{aligned}
& \text { the } \ell \text { curve: } \quad R=\beta / u^{\prime}(c), \\
& \text { the } \pi \text { curve: } \quad R=\rho+\alpha\left[c / y^{f}(c ; \tau, s, \theta, \gamma)-1\right] .
\end{aligned}
$$

Since $u^{\prime \prime}(\cdot)<0$ and $y_{c}^{f}<0$ from the first property given in (18), both curves of (29) are increasing functions with respect to $c$, as illustrated in Figure 2. Intersection point E denotes the steady state in which $c$ is smaller than $c^{f}$, the full-employment level of consumption per capita. Since under (28) the $\ell$ curve is located above the $\pi$ curve, as shown by the Figure 2, in order for this $c$ to exist, the following must be satisfied:

$$
\beta / u^{\prime}\left(c^{f}\right)>\rho>\alpha .
$$

As is also evident from Figure 2, under (30) the $\ell$ curve is more inclined than the $\pi$ curve at the intersection point, i.e., ${ }^{10}$

$$
\Lambda=-\beta u^{\prime \prime}(c) /\left[u^{\prime}(c)\right]^{2}-\alpha\left[1 / y^{f}(c ; \tau, s, \theta, \gamma)-c y_{c}^{f} /\left(y^{f}\right)^{2}\right]>0 .
$$

From (29) we obtain

$$
\Lambda d c=-\left[\alpha c /\left(y^{f}\right)^{2}\right] y_{i}^{f} d i \quad(\text { for } i=\tau, s, \theta, \gamma) .
$$

By comparing (32) with (24) we find

Lемма 1. If unemployment arises in the steady state, the effect of an increase in each (policy or technology) parameter (i.e., $\tau, s, \theta, \gamma$ ) on consumption per capita is just opposite to what obtains when full employment is realized in the steady state.

Figure 3 illustrates the effect of an increase in $\tau$, an increase in $s$ or a decrease in $\theta$. From (18), each of them exogenously reduces $y^{f}$ and thus shifts the $\pi$ curve upward toward the $\pi^{\prime}$ curve, moving the intersection point of the two curves from $\mathrm{E}$ to $\mathrm{E}^{\prime}$. Consequently, per capita

\footnotetext{
${ }^{10}$ In the appendix it is shown that (30) must hold for the present dynamics to be saddle-path stable.
} 
consumption $c$ increases from $c_{1}$ to $c_{2}$ while full-employment consumption per capita $c^{f}$ decreases from $c_{1}^{f}$ to $c_{2}^{f}$.

From (19), at the intersection point given by (29)

$$
\beta / u^{\prime}(c)=\rho+\alpha(x-1),
$$

from which we obtain

$$
\left\{-\beta u^{\prime \prime}(c) /\left[u^{\prime}(c)\right]^{2}\right\} d c=\alpha d x
$$

Therefore, employment rate $x$ moves in the same direction as $c$ does.

Since (29) yields $c$ as a function of $\tau, s, \theta$ and $\gamma$, totally differentiating (15) leads to

$$
d n=\left(n_{c} d c / d \tau+n_{\tau}\right) d \tau+\left(n_{c} d c / d s+n_{s}\right) d s+\left(n_{c} d c / d \theta\right) d \theta+\left(n_{c} d c / d \gamma+n_{\gamma}\right) d \gamma
$$

From (16), (18), (32) and (34), we obtain

$$
d n / d \tau>0, d n / d s>0, d n / d \theta<0 .
$$

The effect of an increase in $\gamma$ on $n$ is calculated in the appendix. It satisfies

$$
d n / d \gamma<0
$$

Thus, from lemma 1, (33), (35) and (36), the following proposition obtains.

Proposition 2. If unemployment arises in the steady state, an increase in child allowance $\tau$ or income tax s raises the fertility rate, consumption per capita and the employment rate. An increase in productivity $\theta$ decreases the fertility rate, consumption per capita and the employment rate. An increase in the efficiency of child rearing (viz. a decrease in $\gamma$ ) always increases the fertility rate, but the effects on per capita consumption and the employment rate are ambiguous. More precisely,

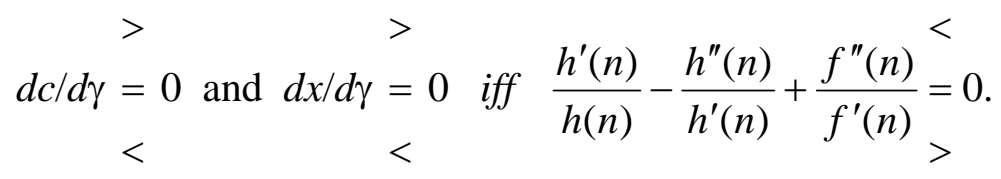

Intuitively, the child allowance policy urges people to have more children and thus decreases labor supply. In the presence of unemployment it reduces the deflationary gap, causing consumption to increase. Wage income tax s reduces net income from labor supply and hence decreases the opportunity cost of child rearing. It urges people to have more children and 
decreases labor supply, which generates the same positive effect on per capita consumption as the child allowance policy does. An improvement in productivity $\theta$ widens the deflationary gap and increases deflation, which causes people to decrease consumption. It then reduces wage income and hence people decrease the number of children.

A decrease in $\gamma$ (viz. an improvement in the efficiency of child rearing) increases the number of children, but the amount of labor that is required to rear each child decreases. Therefore, the effect on the labor allocation between child rearing and labor supply is ambiguous. It also implies that the effect on household consumption is ambiguous.

\section{Conclusion}

Various policies that promote fertility increase total labor endowment, but reduce labor supply per capita because parents have to take care of children. Thus, if full employment is always realized, they reduce consumption per capita. For example, a rise in the child allowance or the wage tax reduces the opportunity cost of child rearing, causing people to have more children and lower labor supply to the market. Thus, consumption per capita decreases.

In the presence of unemployment, however, the decrease in the labor supply caused by a pro-population policy reduces the deflationary gap, lowers deflation and thus stimulates consumption per capita. The effects of such policies in the presence of unemployment are just opposite to those under full employment.

An improvement in the efficiency of child rearing (e.g., nursery schools and kindergartens) generates two opposite effects on consumption. It decreases the volume of labor required to rear each child and hence increases labor supply as long as the number of children is invariant. However, it increases the fertility rate, which requires parents to allocate more labor to take care of children and thus lowers labor supply to the labor market. Therefore, the labor supply per capita can either increase or decrease, depending on the shape of the utility function of having children and that of the cost function of child rearing. If it increases, consumption per capita increases as long as full employment is realized, whereas in the presence of unemployment it decreases, and vice versa. The effects of the policies that affect the fertility rate in the presence of unemployment are just opposite to those under full employment. 


\section{Appendix}

\section{Derivation of equation (36)}

From (17), (18), (32) and (34),

$$
\Lambda d n / d \gamma=n_{c} \alpha c h(n) /\left[\theta(1-\gamma h(n))^{2}\right]+\left\{\Lambda+n_{c} \alpha c \gamma h^{\prime}(n) /\left[\theta(1-\gamma h(n))^{2}\right]\right\} n_{\gamma} .
$$

From (17), $y_{c}^{f}$ in (18), and (29), $\Lambda$ given by (31) satisfies

$$
\Lambda+n_{c} \alpha c \gamma h^{\prime}(n) /\left[\theta(1-\gamma h(n))^{2}\right]=(\rho-\alpha) \sigma / c+\alpha(\sigma-1) /[\theta(1-\gamma h(n))] .
$$

Using (15) in which $s=0$ and $\tau=0$, and $n_{c}$ and $n_{\gamma}$ given by (16), we obtain

$$
n_{c}=-n_{\gamma}[1-\gamma h(n)](\sigma-1) \gamma / c \text {. }
$$

Substituting (A2) and (A3) into (A1) and rearranging the result gives

$$
\Lambda d n / d \gamma=[\alpha(\sigma-1) / \theta+(\rho-\alpha) \sigma / c] n_{\gamma} .
$$

Since $\sigma \geq 1$ from (5), $n_{\gamma}<0$ from (16), $\rho>\alpha$ from (30), and $\Lambda>0$ from (31), $d n / d \gamma$ is negative, as described in (36).

\section{Dynamic stability}

We examine the stability of the dynamics described by (20) and (21). For simplicity, we treat the case where child allowance $\tau$ and wage income tax $s$ are both zero. Let $k=1 / m$, substituting (17) into (20) and (21) yields

$$
\begin{gathered}
\dot{c}=\frac{c}{\sigma}\left[\frac{v^{\prime}(1 / k)}{u^{\prime}(c)}-\rho-\alpha\left(\frac{c}{y^{f}(c)}-1\right)\right], \\
\dot{k}=k \pi=k\left[\alpha\left(\frac{c}{y^{f}(c)}-1\right)\right] .
\end{gathered}
$$

Linearizing them in the neighborhood of the steady state values $\left(c^{*}, k^{*}\right)$ gives

$$
\left(\begin{array}{l}
\dot{c} \\
\dot{k}
\end{array}\right)=\left[\begin{array}{ll}
A_{1} & A_{2} \\
A_{3} & A_{4}
\end{array}\right]\left(\begin{array}{l}
c-c^{*} \\
k-k^{*}
\end{array}\right),
$$

where 


$$
\begin{gathered}
A_{1}(\equiv \partial \dot{c} / \partial c)=\frac{c}{\sigma}\left[\frac{-u^{\prime \prime}(c) v^{\prime}(1 / k)}{\left[u^{\prime}(c)\right]^{2}}-\alpha\left[1 / y^{f}-c y_{c}^{f} /\left(y^{f}\right)^{2}\right],\right. \\
A_{2}(\equiv \partial \dot{c} / \partial k)=-\frac{c}{\sigma}\left[\frac{v^{\prime \prime}(1 / k)}{u^{\prime}(c) k^{2}}\right], \\
A_{3}(\equiv \partial \dot{k} / \partial c)=k \alpha\left[1 / y^{f}-c y_{c}^{f} /\left(y^{f}\right)^{2}\right], \\
A_{4}(\equiv \partial \dot{k} / \partial k)=\pi=\alpha\left(c / y^{f}-1\right) .
\end{gathered}
$$

Since the characteristic equation is

$$
\Psi(\lambda)=\lambda^{2}-\left(A_{1}+A_{4}\right) \lambda+\left(A_{1} A_{4}-A_{2} A_{3}\right),
$$

eigenvalues $\lambda_{1}$ and $\lambda_{2}$ satisfy

$$
\begin{aligned}
\lambda_{1} \lambda_{2}=A_{1} A_{4}-A_{2} A_{3} & =\frac{c}{\sigma}\left[\frac{-u^{\prime \prime}(c) v^{\prime}(1 / k)}{\left[u^{\prime}(c)\right]^{2}}-\alpha\left[1 / y^{f}-c y_{c}^{f} /\left(y^{f}\right)^{2}\right]\right] \pi \\
& +\frac{c}{\sigma}\left[\frac{v^{\prime \prime}(1 / k)}{u^{\prime}(c) k}\right] \alpha\left[1 / y^{f}-c y_{c}^{f} /\left(y^{f}\right)^{2}\right] .
\end{aligned}
$$

If full employment is reached in the steady state, $\pi=0$ and hence the first term of (A5) becomes to zero. Since $y_{c}^{f}<0$ from (18) and $v^{\prime \prime}()<$.0 , the second term is negative. Thus, $\lambda_{1} \lambda_{2}$ $<0$, implying that one of the eigenvalues is positive and the other is negative. Since $c$ is jumpable and $k(\equiv 1 / m)$ is non-jumpable, the dynamic path is saddle-point stable.

If there is no full-employment steady state and persistent stagnation arises, $x<1$ and $\pi<0$ in the steady state. Therefore, $k(\equiv 1 / m)$ approaches zero and the value given by the square brackets of the first term of (A5) equals $\Lambda$, which is positive from (31). Thus, the first term of (A5) is negative. The second term is negative since $y_{c}^{f}<0$ from (18) and $v^{\prime \prime}()<$.0 . Therefore, (A5) is negative $\left(\lambda_{1} \lambda_{2}<0\right)$, implying that the dynamic path is saddle-point stable. 


\section{References}

Atoh, Makoto, and Mayuko Akachi (2003) "Low Fertility and Family Policy in Japan: In an International Comparative Perspective,” Journal of Population and Social Security: Population Study, Supplement to Volume 1, 1-30.

Becker, Gary S. and Robert J. Barro (1988) “A Reformulation of the Economic Theory of Fertility,” Quarterly Journal of Economics, Vol. 108, 1-25.

Becker, Gary S. and H. Gregg Lewis (1973) “On the Interaction between the Quantity and Quality of Children,” Journal of Political Economy, Vol. 81, 279-288.

Blau, David M. and Philip K. Robins (1989) “Fertility, Employment, and Child-Care Costs,” Demography, Vol. 26, 287-299.

Cai, Donghan (2002) “An Economic Growth Model with Endogenous Fertility: Multiple Growth Paths, Poverty Trap and Bifurcation,” Journal of Computational and Applied Mathematics, Vol. 144, 119-130.

Galor, Oded and David N. Weil (2000) "Population, Technology, and Growth: From Malthusian Stagnation to the Demographic Transition and Beyond," American Economic Review, Vol. 90, 806-828.

Groezen, B. van, Leers, Theo, and Mejidam, Lex (2003) “Social Security and Endogenous Fertility: Pensions and Child Allowances as Siamese Twins,” Journal of Public Economics, Vol. 87, 233-251.

Guvenen, Fatih (2006) "Reconciling Conflicting Evidence on The Elasticity of Intertemporal Substitution: A Macroeconomic Perspective,” Journal of Monetary Economics, Vol. 53, 1451-1472.

Nerlove, Marc, Assaf Razin, and Efraim Sadka (1987) Household and Economy: Welfare Economics of Endogenous Fertility, Academic Press: New York.

Nerlove, Marc and Lakshmi K. Raut (1997) “Growth Models with Endogenous Population: A General Framework,” In: Rosenzweig, M.R., Stark O. (Eds.), Handbook of Population and Family Economics, Vol. 1B. North Holland: Amsterdam, 1117-1174.

OECD (2006) OECD Health Data 2006, The Organization for Economic Co-operation and Development, Paris.

Ono, Yoshiyasu (1994) Money, Interest, and Stagnation - Dynamic Theory and Keynes's Economics, Oxford University Press. 
Ono, Yoshiyasu (2001) “A Reinterpretation of Chapter 17 of Keynes's General Theory: Effective Demand Shortage under Dynamic Optimization”, International Economic Review, Vol. 42, 207-236.

Ono, Yoshiyasu, Kazuo Ogawa and Atushi Yoshida (2004) "Liquidity Preference and Persistent Unemployment with Dynamic Optimizing Agents: Empirical Evidence”, Japanese Economic Review, Vol. 55, No.4, 355-371.

Palivos, Theodore (1995) “Endogenous Fertility, Multiple Growth Paths, and Economic Convergence,” Journal of Economic Dynamics and Control, Vol. 19, 1489-1510.

Petrucci, Alberto (2003) “Money, Endogenous Fertility and Economic Growth,” Journal of Macroeconomics, Vol. 25, 527-539.

Razin, Assaf and Uri Ben-Zion (1975) “An Intergenerational Model of Population Growth,” American Economic Review, Vol. 65, No. 5, 923-933.

Razin, Assaf and Sadka Efraim (1995) Population Economics, MIT Press: Cambridge, MA.

Sidrauski, Miguel (1967) "Rational Choice and Pattern of Growth in a Monetary Economy,” American Economic Review, Vol. 57, 534-544.

Tabata, Ken (2003) “Inverted U-shaped Fertility Dynamics, the Poverty Trap and Growth,” Economics Letters, Vol. 81, 241-248.

Tamura, Robert (1996) "From Decay to Growth: A Demographic Transition to Economic Growth,” Journal of Economic Dynamics and Controll, Vol. 20, 1237-1261.

Wang, Ping, Chong K Yip, and Carol A. Scotese (1994) "Fertility Choice and Economic Growth: Theory and Evidence,” Review of Economics and Statistics, Vol. 76, 255-266.

Yip, Chong K. and Junxi Zhang (1996) "Population Growth and Economic Growth: A Reconsideration,” Economics Letters, Vol. 52, 319-324.

Yip, Chong K. and Junxi Zhang (1997) “A Simple Endogenous Growth Model with Endogenous Fertility: Indeterminacy and Uniqueness,” Journal of Population Economics, Vol. 10, 97-110. 


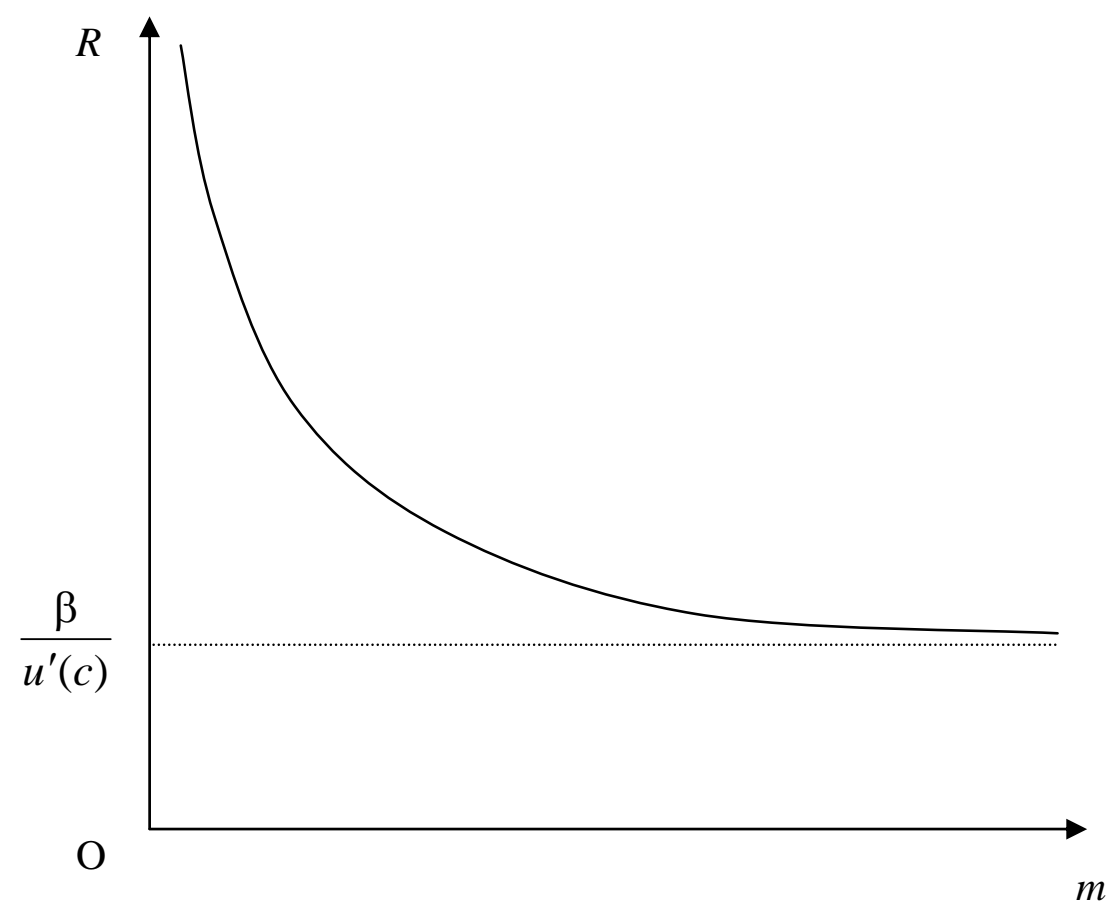

Figure 1: Money Demand with a Liquidity Trap 


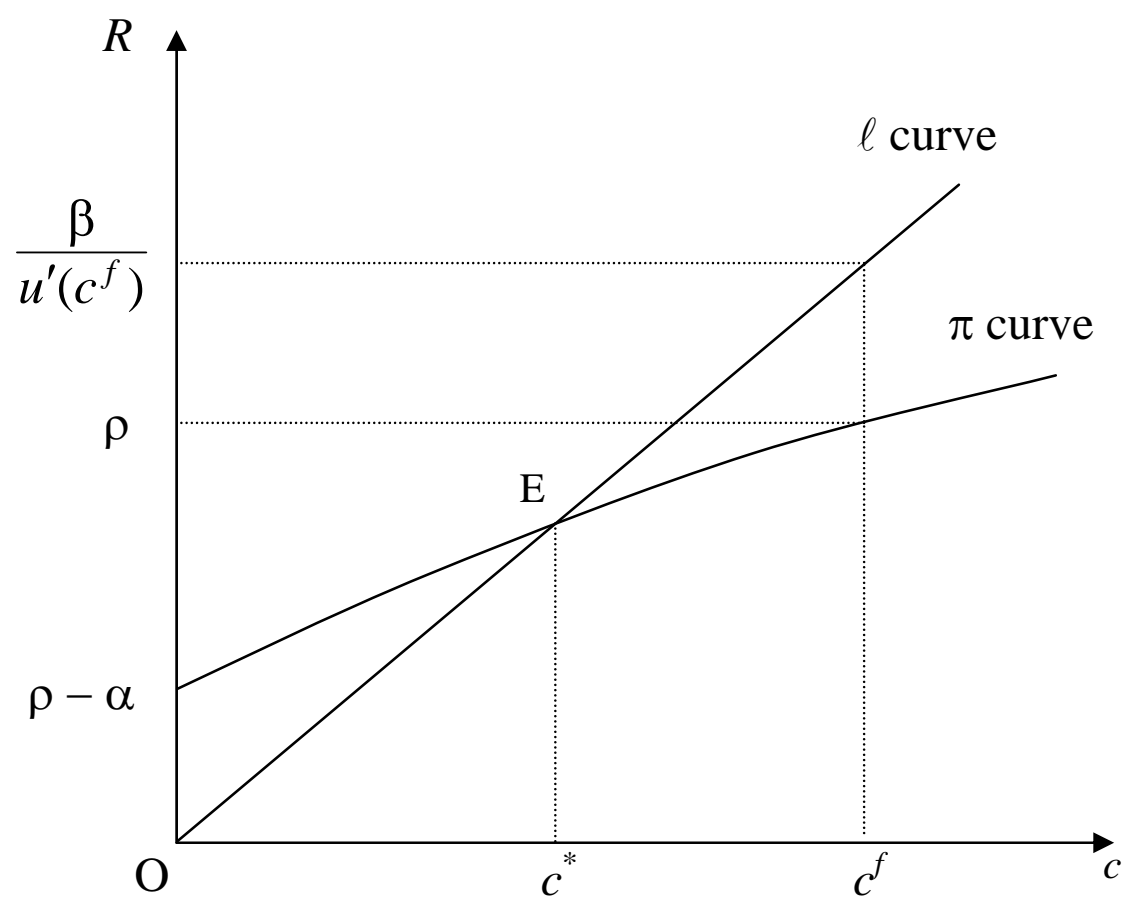

Figure 2: Stagnation Steady State 


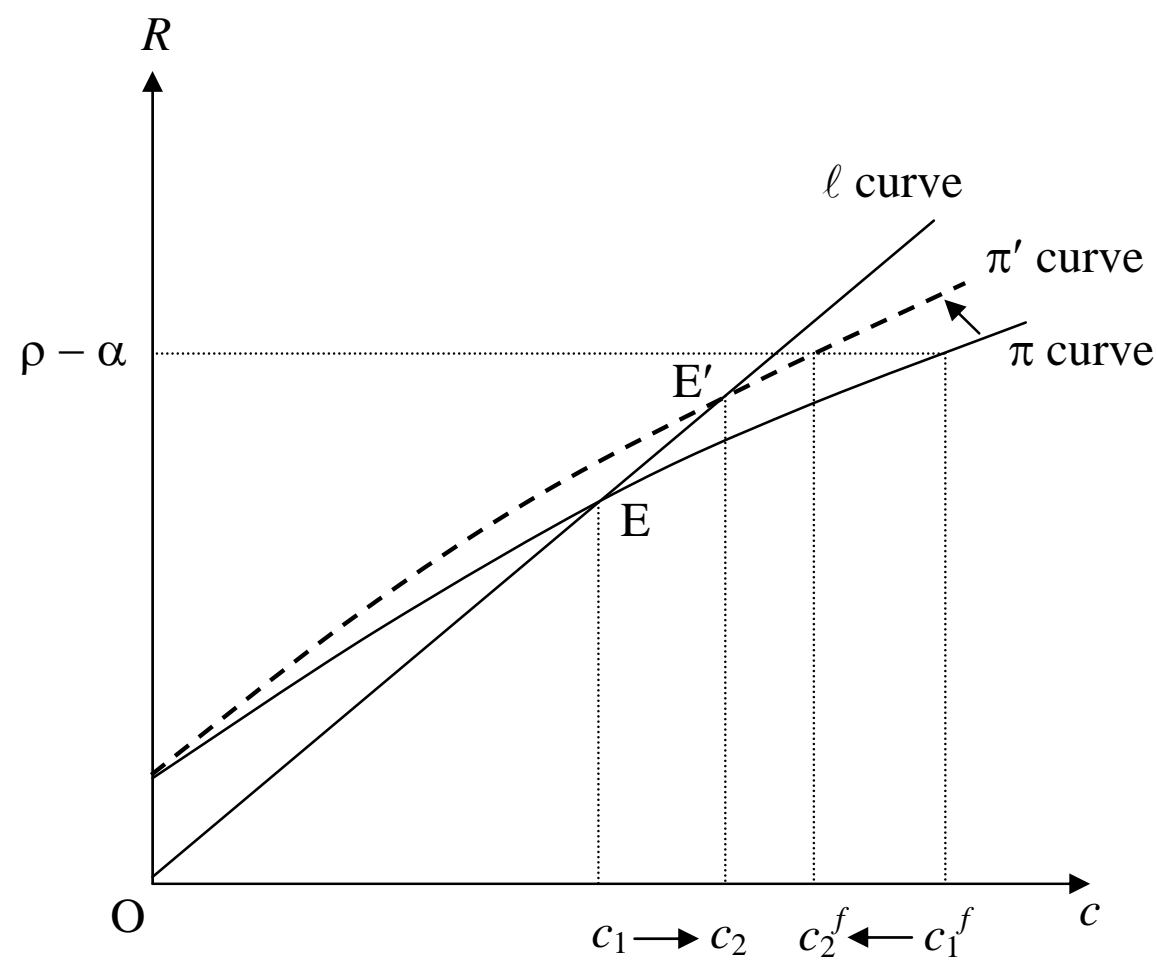

Figure 3: Pro-population Policies 